\title{
Elementy rozrywki w muzycznej audycji towarzyszącej na przykładzie programów $z$ wybranych rozgłośni komercyjnych
}

Odbiorcy medialnych treści w czasie wolnym od pracy zawodowej [o poranku i po południu] poszukują dla siebie rozluźnienia, rozrywki, swego rodzaju przyjemności. Należałoby się jednak zastanowić, czy tego rodzaju potrzeby nie uwidaczniają się również w ciągu dnia, w trakcie nauki, wykonywania pracy lub innych czynności, np. zajęć domowych? Badacze kultury współczesnej twierdzą bowiem, że obecnie poczucie „braku czasu” jest tak silnie zakorzenione w naturze ludzkiej, że poszczególne jednostki stawiają na wielozadaniowość i starają się jednocześnie zaspakajać szereg różnych potrzeb².

[...] działamy w trybie wielozadaniowym, jesteśmy koneserami wielozadaniowości, ekspertami od upychania, ściskania, pakowania i nakładania różnych aktywności w nazbyt skończonych momentach czasu. Owa wielozadaniowość to nie zabijanie czasu i nie jego spędzanie, lecz opanowanie - to daje poczucie mocy i satysfakcji³.

Tym samym dochodzi m.in. do zacierania się granic między czasem wolnym a pracą, między czynnościami obowiązkowymi a zabawą, produkcją

* Dr, e-mail: paulina.czarnek@uni.lodz.pl; Uniwersytet Łódzki, Wydział Filologiczny, Katedra Dziennikarstwa i Komunikacji Społecznej; 90-236 Łódź, ul. Pomorska 171/173.

${ }^{1}$ Por. W. Muszyński, Syndrom braku czasu we współczesnym społeczeństwie, [w:] „Nowy wspaniaty świat?" Moda, rozrywka i konsumpcja jako nowe style życia, red. W. Muszyński, Wydawnictwo Adam Marszałek, Toruń 2009, s. 7-19.

${ }^{2}$ Rozważając relację między czasem wolnym a czasem pracy, warto przytoczyć opinię Jerzego Szeji, który sądzi, iż to zabawa właściwa czasowi wolnemu jest silniej zakorzeniona w kulturze niż praca. Dlatego też przewiduje, iż w przyszłości zabawę i pracę będzie można ze sobą łączyć pod warunkiem prawidłowego wykonywania wszystkich swoich obowiązków [J.Z. Szeja, Cywilizacja zabawy? Próba spojrzenia w przyszłość, „Homo communicativus” 2008, nr 3 (5), s. 152].

${ }^{3}$ D. Mroczkowska, Szybkość i pośpiech jako źródła przyjemności, [w:] Kultura przyjemności. Rozważania kulturoznawcze, red. J. Grad, H. Mamzer, Wydawnictwo Naukowe Uniwersytetu im. Adama Mickiewicza, Poznań 2005, s. 124. 
a konsumpcją ${ }^{4}$ Ta ostatnia zaś realizowana jest w ciągłym pośpiechu, poczuciu konieczności wykonania konkretnych zadań, nawet tych przyjemnościowych, w możliwie skondensowany i szybki sposób. „Zdolność do szybkiej pracy i szybkiej zabawy daje poczucie mocy, ożywienie [...]"5.

Biorąc pod uwagę tego rodzaju obserwacje dotyczące zachowań przedstawicieli współczesnych społeczeństw, szczególnie tych wysoko rozwiniętych, zdecydowałam się przełożyć zjawisko wielozadaniowości na grunt radia i sprawdzić, w jaki sposób medium audialne zaspokaja potrzebę łączenia obowiązków zawodowych ze swoiście pojętym relaksem. Jako materiał badawczy wykorzystane zostały audycje towarzyszące, które można usłyszeć w rozgłośniach komercyjnych w ciągu dnia, zazwyczaj między 9.00 a 15.00 oraz w weekendy w podobnym przedziale czasowym [programy o takim charakterze funkcjonują również $\mathrm{w}$ nieco mniej popularnych w odniesieniu do radia godzinach, czyli wieczorem i w nocy], np. „Byle do piątku” czy wakacyjne „Lato wszędzie” i „Czas letni” w RMF FM, „Od ucha do ucha”, „Muzyka, informacje, zabawa!” i letnie mutacje „Upalne granie bez cienia mówienia”, „Lato Zet” w Radiu Zet [wcześniej np. „Radio Zet - to lubię”], „Dziesięć hitów jeden po drugim” czy „ImprEska” w Radiu Eska. W odniesieniu do wybranych zagadnień korzystam także z przykładów zaczerpniętych z innych rozgłośni - np. z Radia Złote Przeboje czy Vox FM. Za cel badawczy postawiłam sobie udowodnienie tezy, że muzyczne audycje towarzyszące emitowane przez stacje komercyjne proponują swoim słuchaczom głównie rozrywkę. Postaram się zaprezentować, jakie oblicza może ona przybierać.

Oczywiście nie każdy może sobie pozwolić na słuchanie medium audialnego w pracy, jednak taka forma nieinwazyjnej rozrywki jest w tych okolicznościach dość powszechna [wystarczyłoby wymienić chociażby pracowników galerii handlowych, sklepów, zakładów fryzjerskich, niektórych biur, gospodynie domowe, a nawet lekarzy i - co za tym idzie - również osoby pojawiające się w ich otoczeniu]. Jak pisze Grażyna Stachyra, ,,audycja towarzysząca jest gatunkiem powstałym w wyniku zmian społecznych, ekonomicznych [wydłużenie godzin pracy przy jednoczesnym epatowaniu potrzebą relaksu], sprzyjających rozwarstwieniu słuchaczy na listener i hearer" ${ }^{\prime}$. W konsekwencji przemian, jak chociażby wzrost mobilności, tempa życia, spędzanie w pracy większości dnia, ,[...] producenci radiowi tworzą gatunki «tła» umożliwiające «słyszenie» radia (hearing), co jest domeną stacji komercyjnych"7.

${ }^{4}$ E. Krawczak, Medialne formy spędzania czasu wolnego, [w:] „Małe tęsknoty?” Style życia w czasie wolnym we współczesnym społeczeństwie, red. W. Muszyński, Wydawnictwo Adam Marszałek, Toruń 2009, s. 70.

${ }^{5}$ D. Mroczkowska, dz. cyt., s. 127.

${ }^{6}$ G. Stachyra, Gatunki audycji w radiu sformatowanym, Wydawnictwo Uniwersytetu Marii Curie-Skłodowskiej, Lublin 2008, s. 145.

7 Tamże. 
Nadawcy stawiają wówczas na muzykę, konkursy i lapidarne wypowiedzi prowadzących oraz dostarczanie niezbędnej porcji aktualnych doniesień z kraju i z zagranicy. Zależy im bowiem na tym, by zbytnio „nie zmęczyć” słuchaczy obecnością radia $\mathrm{w}$ ich otoczeniu i nie zakłócić obowiązków, jakie mają w tym czasie do wykonania. Takie podejście owocuje w dużej mierze sięganiem po gatunki i treści o charakterze rozrywkowym [niezbyt jednak angażujące audytorium] po to, by zapewnić odbiorcom możliwie przyjemne spędzanie czasu w pracy bądź też czasu wolnego.

Zasada przyjemności organizuje działania [i motywy postępowania] oraz wyznacza sposoby ich realizowania. Ludzie niezależnie od warunków dążą do zaznawania przyjemności, radowania, cieszenia się, które współcześnie coraz częściej odnajdują w natychmiastowości, doraźnych rozwiązaniach, upraszczaniu i skracaniu wykonywanych czynności $[\ldots]^{8}$.

W odniesieniu do przekazu radiowego może to owocować jego znacznym spłaszczeniem, ślizganiem się po powierzchowni podejmowanych zagadnień tak, by były one jak najmniej absorbujące. Dewaluacja serwowanych treści, m.in. poprzez sposób ich przekazywania, przyczynia się - jak wieścił autor Technopolu - do obniżenia poziomu szeroko pojętej kultury współtworzonej przecież przez środki masowego przekazu.

W sytuacji, gdy ludzkość jest oszałamiana przez banał, kiedy życie kulturalne zostaje zdefiniowane na nowo jako nieustające pasmo rozrywki, kiedy publiczna rozmowa upodabnia się do niemowlęcego gaworzenia, kiedy wreszcie społeczeństwo staje się widownią, a jego interes publiczny wodewilowym spektaklem - narodowi zagraża niebezpieczeństwo, a możliwość śmierci kultury staje się nieunikniona9.

- dosadnie zapowiadał Neil Postman.

Jednym z przejawów wspomnianej tendencji do trywializowania treści dostarczanych przez radiostacje komercyjne jest sposób tworzenia wejść antenowych. W tradycyjnej audycji autorskiej ${ }^{10}$ to prowadzący miał duży wpływ na

${ }^{8}$ D. Mroczkowska, dz. cyt., s. 117.

${ }^{9}$ N. Postman, Zabawić się na śmierć. Dyskurs publiczny w epoce show-businessu, przekł. L. Niedzielski, Wydawnictwo Muza SA, Warszawa 2002, s. 220.

${ }^{10}$ Niektóre audycje towarzyszące w radiu komercyjnym zbliżają się w stronę programów autorskich np. „Taniec z Bryndalem” Rafała Bryndala, „Świat według blondynki” Beaty Pawlikowskiej w Radiu Zet czy „RMF Extra” [wcześniej „Szoł”] Marty Grzywacz i Piotra Jaworskiego w RMF FM. W audycjach tych emitowanych - i to element dość charakterystyczny - w weekendy można zaobserwować bardziej widoczną kreację osobowości prowadzącego, który nie pojawia się na antenie tylko jako „przerywnik” pomiędzy następującymi po sobie utworami muzycznymi, ale nadaje programowi specyficzny koloryt, naznacza go swoją osobowością. 
to, w jaki sposób wyglądał program, jakie treści były w nim poruszane. Tym samym mógł w dość znacznym stopniu odcisnąć na nim swoje indywidualne, twórcze piętno. W audycjach towarzyszących w stacjach komercyjnych sytuacja wygląda zgoła odmiennie. Prowadzący tylko pośrednio mogą decydować o tym, co pojawi się w programie. Warstwa muzyczna zazwyczaj zajmuje $70-80 \%$ czasu trwania audycji [stąd często określa się ją mianem muzycznej]. Poza nią pojawiają się bloki reklamowe, serwisy informacyjne, elementy autopromocji [dżingle i linery stacji oraz promosy programów, konkursów] oraz właściwe wejścia antenowe stanowiące podstawowy, choć zredukowany do minimum, komponent warstwy słownej programu. Tematy w nich poruszane mają bardzo często charakter okolicznościowy i są związane z aktualnymi wydarzeniami, stronią jednak od polityki czy gospodarki, a skupiają się na sprawach ludziom bliskich, przyziemnych [dominuje raczej tematyka obyczajowa, ewentualnie kulturalna]. Prowadzący podejmują kwestie „bezpieczne”, niebudzące kontrowersji, co czyni wejścia antenowe lapidarnymi, niekiedy nawet banalnymi, niewiele wnoszącymi komentarzami. Co najwyżej wzbudzają one uśmiech odbiorcy za sprawą dość często wykorzystywanych przez dziennikarzy kickerów, czyli zabawnych informacji, ciekawostek.

Zazwyczaj każda audycja ma swój temat przewodni, który pojawia się przez cały czas jej trwania, jest poruszany przez prowadzącego oraz komentowany przez odbiorców za pomocą call-ins bądź też dyskusji na profilu stacji w mediach społecznościowych, głównie na Facebooku. Oddanie głosu słuchaczom nie świadczy jednak o bezinteresowności nadawców. Zależy im bowiem na tym, by poprzez takie przejawy swoistej medialnej demokracji zbudować pozytywny wizerunek, który w dalszym etapie przełoży się na wyniki słuchalności. Do opisu tego zjawiska może posłużyć pojęcie democratainment wykorzystane na gruncie polskiej myśli badawczej m.in. przez Małgorzatę Lisowską-Magdziarz.

Democratainment opiera się na złudzeniu uczestnictwa i wpływu [specjaliści od wizerunku wolą mówić: na interaktywności]. Widz, czytelnik, słuchacz dostaje kawałek rozrywki. Za skonsumowanie tego kawałka nagradza się go wrażeniem, że media realizują jego prawo do informacji [...]; że mówią one w jego imieniu, reprezentują jego opinie i interesy; że pozwalają mu się wypowiedzieć ${ }^{11}$.

Stacje komercyjne w swoich działaniach skupiają się na gromadzeniu dość spójnego i stałego audytorium, które będzie gwarantowało zyski. W tym celu podejmują one szereg działań mających na celu zbudowanie pożądanego wizerunku

${ }^{11}$ M. Lisowska-Magdziarz, Media powszednie. Środki komunikowania masowego i szerokie paradygmaty medialne w życiu codziennym Polaków u progu XXI wieku, Wydawnictwo Uniwersytetu Jagiellońskiego, Kraków 2008, s. 238. 
i zdobycie zaufania odbiorców. Najczęściej uzyskują one rozrywkowe zabarwienie. Wszak

we współczesnym społeczeństwie dominuje cywilizacja gry i zabawy; praca, wysiłek nie stanowią już wartości podstawowych. Zadania środków społecznego przekazu, dawniej uważane za fundamentalne, a mianowicie informowanie, opisywanie i komentowanie rzeczywistości, edukowanie oraz wychowywanie, zostały więc zredukowane i zdominowane przez funkcję rozrywkową; nawet bowiem informacje dziennikarskie mają odbiorcom sprawiać przyjemność ${ }^{12}$.

\section{- pisał Grzegorz Łęcicki.}

W audycjach towarzyszących można jednak znaleźć formy rozrywki zawierające $\mathrm{w}$ sobie pewne walory poznawcze ${ }^{13}$. Jednym z przykładów tego rodzaju audycji jest program Jacka Tomkowicza pt. „Gdzieś to już słyszałem” emitowany w Radiu RMF FM w środy po godzinie 12.00 w obszernym, towarzyszącym bloku programowym pod nazwą „Byle do piątku” [pierwszy odcinek ukazał się na początku lipca 2013 roku]. Ma on również swój audiowizualny odpowiednik w postaci filmów publikowanych na stronie internetowej rozgłośni oraz jej profilu w serwisie You Tube. Taki dualny sposób dystrybucji treści przekazywanych w programie wynika z jego charakteru. „Gdzieś to już słyszałem” można - w moim przekonaniu - określić mianem muzycznego kącika tematycznego prezentowanego w ,śledczej” konwencji. Tomkowicz w każdym z odcinków audycji przedstawia bowiem znane przeboje będące oficjalnymi coverami bądź też plagiatami innych utworów wraz z ich pierwowzorami. Szczegółowo omawia źródło inspiracji oraz historię poszczególnych wykonań. Piosenki prezentowane w każdym wydaniu programu powiązane są wspólnym hasłem, wybory dziennikarza nie są więc przypadkowe [np. „Sean Paul pod lupą!” w odcinku 8, „Polacy nie gęsi!” z odcinka 56 czy „Plagiaty legend” z odcinka 81]. Dość często Tomkowicz korzysta także ze wskazówek słuchaczy, którzy mogą - poprzez swoje sugestie - współtworzyć program. Tym samym zyskuje on otwarty charakter, staje się swego rodzaju obywatelską platformą, będącą efektem porozumienia na linii autor-odbiorca.

Audycja stanowi swoiste połączenie rozrywki, przyjemności czerpanej z kontaktu ze znanymi utworami, nierzadko przywodzącymi na myśli wydarzenia z młodości, z niewielkimi walorami edukacyjnymi uwidaczniającymi się

${ }^{12}$ G. Łęcicki, Integracyjna oraz dezintegrująca funkcja mediów w społeczeństwie informacyjnym, ,Kultura - Media - Teologia” 2011, nr 4, s. 52.

${ }^{13}$ Do grupy tej zaliczyłabym również np. „Technologikę” Krzysztofa Kurka [informacje na temat nowinek technicznych], „Doktora Zet” Wojciecha Jagielskiego [porady medyczne], „100 buntowników, którzy zmienili świat”, „100 wynalazków, które zmieniły świat” Rafała Turowskiego [ciekawostki historyczne]. Wszystkie audycje pochodzą z Radia Zet. 
w pokazywaniu chwytów wykorzystywanych przez twórców muzyki rozrywkowej. Można by więc pokusić się o stwierdzenie, że w przypadku programu „Gdzieś to już słyszałem” mamy do czynienia z edurozrywką rozumianą jako czerpanie pewnej wiedzy z działań o zabawnym charakterze. Magdalena Piechota sądzi, że anglojęzyczny termin edutainment można na język polski tłumaczyć dwojako - jako edurozrywkę właśnie [zakładającą pasywną postawę podmiotu uczącego się przy okazji wypełniania czasu rozrywką] i eduzabawę [zakładającą aktywną postawę podmiotu uczącego się poprzez udział w zabawie $]^{14}$. Zdaniem badaczki zdecydowanie bardziej skuteczną formą oddziaływania na odbiorców jest druga $\mathrm{z}$ odmian edutainment zakładająca większe zaangażowanie. $\mathrm{W}$ jej bowiem przypadku istnieje znaczniejsza szansa na to, że przekazywane w trakcie owej interakcji treści zostaną sobie przez publiczność uświadomione i odpowiednio przetworzone.

Eduzabawa, poprzez uczynienie z odbiorcy [...] współautora i współkreatora wydarzeń [...] oraz zrównanie celów [zabawa i nauka jednocześnie] dużo skuteczniej prowadzi do zmiany poznawczej, choćby cząstkowej. [...] Zabawa wyzwala niezmierzone pokłady inwencji i gotowość do stawiania sobie pytań i odpowiadania na nie, zamiast przyswajania gotowych porcji informacji w celu odpowiedzi na pytania stawiane przez innych ${ }^{15}$.

- pisze autorka.

I takiego również potencjału można by się w programie Jacka Tomkowicza doszukać. Słuchacze jego audycji zachęcani są bowiem do tego, by przesyłać prowadzącemu propozycje utworów, które mogłyby się w niej pojawić. W każdym odcinku prezenter decyduje się korzystać z pomysłów swoich odbiorców, tworzy również specjalne odcinki zainspirowane przez słuchaczy, tak więc należałoby uznać, że „Gdzieś to już słyszałem” - w zależności od stopnia ich zaangażowania - funkcjonuje zarówno jako forma edurozrywki, jak i eduzabawy.

Do czystej, bardzo tradycyjnej formy rozrywki, obecnej nie tylko w medium audialnym, zaliczyć można programy kabaretowe. Nie mają one zazwyczaj bardzo rozbudowanej formuły, ale pojawiają się niemalże w każdej stacji radiowej i są prowadzone przez znane osobistości czy też grupy kabaretowe. Zazwyczaj umieszcza się je właśnie w audycjach towarzyszących lub - ewentualnie - programach porannych. Przyjrzyjmy się w takim razie, jak wygląda oferta miniaudycji satyrycznych i kabaretowych w stacjach komercyjnych.

Od 30 października 2012 roku na antenie Radia RMF FM we wtorkowe przedpołudnia, we wspomnianej już audycji towarzyszącej „Byle do piątku”,

${ }^{14}$ M. Piechota, Strategie edutainment a sytuacja komunikacyjna, [w:] Nowe zjawiska w języku, tekście i komunikacji III. Kontekst a komunikacja, red. I. Matusiak-Kempa, S. Przybyszewski, Centrum Badań Europy Wschodniej UWM, Olsztyn 2011, s. 360.

${ }^{15}$ Tamże. 
pojawiał się rodzaj zabawnego komentarza rysownika Andrzeja Mleczki ${ }^{16}$ pod nazwą „Tydzień pod kreską” [jego emisja została zakończona w czerwcu 2013 roku]. Realizowany był on dwojako - posiadał bowiem wersję słowną emitowaną na antenie i wizualną publikowaną na stronie internetowej stacji, które łączył wspólny temat. Pierwsza z nich tworzona była wraz z prowadzącym audycję, wypowiedzi Andrzeja Mleczki były wcześniej zarejestrowane, a następnie wyemitowane na antenie stosownie do pytań prezentera. Wskazywało na to chociażby odmienne tło dźwiękowe pojawiające się w komentarzach rysownika, nie tak akustycznie czyste, jak dzieje się to w przypadku nagrań zarejestrowanych w studiu. Na końcu każdego z nich prowadzący zachęcał do zapoznania się z rysunkiem Andrzeja Mleczki zamieszczonym na www.rmf.fm. I to właśnie drugi z wymienionych elementów „Tygodnia pod kreską" realizowany był na sposób rozrywkowy, w formie zabawnego, rysunkowego komentarza do tematu przewodniego danego odcinka serii [przykład znajduje się poniżej].

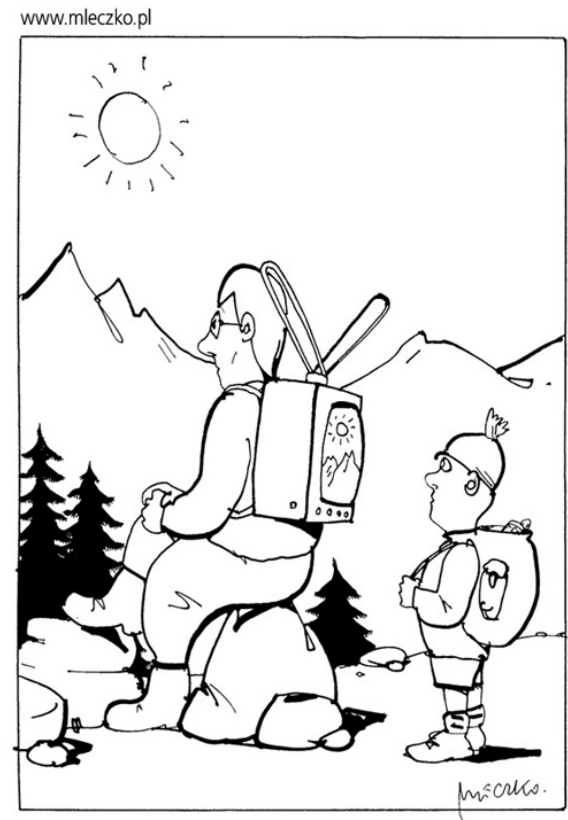

Rys. 1. Szkic Andrzeja Mleczki pt. „Widoki na weekend”

Źródło: A. Mleczko, Widoki na weekend, [w:] Tydzień pod kreska, http://www.rmf.fm/ $\mathrm{au} / \mathrm{a}=\mathrm{bdp} \& \mathrm{p}=$ tydzien-pod-kreska\&pid=24 [dostęp: 13.07.2016].

${ }^{16}$ Wcześniej, w 2011 r., Andrzej Mleczko prowadził w RMF FM audycję „Galeria Andrzeja Mleczki". 
W moim przekonaniu sam pomysł zaangażowania rysownika do tworzenia audycji radiowej wydaje się dość interesujący. Stacja próbowała w ten sposób nieco odejść od swojego awizualnego charakteru, stając się miejscem dystrybucji przekazu obrazkowego. Oczywiście gdyby nie Internet, działanie to odwoływałoby się tylko do wyobraźni odbiorców. W tym przypadku mieli oni natomiast możliwość zarówno posłuchać komentarza Mleczki na antenie, jak i zobaczyć efekt jego pracy w sieci. Oba te elementy „Tygodnia pod kreską" mogłyby funkcjonować samodzielnie, ich przekaz byłby dla odbiorców zrozumiały, jednak dopiero połączenie tych komponentów dawało publiczności możliwość zbudowania pełnego sensu.

Komercyjne rozgłośnie radiowe stają się również miejscem występów grup kabaretowych. Ich doświadczenie w tym względzie nie jest naturalnie tak duże, jak w przypadku rozgłośni publicznych, niemniej jednak i tutaj potencjał satyryków bywa eksploatowany. Przyjrzyjmy się wybranym przykładom.

W Radiu RMF FM od maja 2009 roku do czerwca 2012 roku, dwa razy w tygodniu - we wtorki i w czwartki po 13.30 - można było posłuchać skeczy Kabaretu Pod Wyrwigroszem z cyklu „Między Bugiem a prawdą”. Satyrycy wykorzystali w nim wykreowany na scenach kabaretowych wizerunek prostej, kresowej rodziny [rodzice - Wala, Mieciu i syn Młody] oraz zaprzyjaźnionego z nimi grekokatolickiego duchownego, którzy w zabawny sposób, językiem z widocznymi cechami gwarowymi, komentowali otaczającą ich rzeczywistość. Przygotowywane dla krakowskiej rozgłośni skecze miały charakter „ekskluzywny", tworzone były specjalnie na radiowe zamówienie i - wielokrotnie - kierowane bezpośrednio do słuchaczy RMF FM. Tak, jak w poniższej egzemplifikacji:

Wala: A witajcie.

Pop: Czemu taka radosna dzisiaj?

Wala: Na wakacje polecimy. Na Sri Lankę.

Mieciu: No, Krajaner nowe połączenie uruchomił.

Pop: Eee, to krajowy przewoźnik?

Mieciu: Eee, obcy jak cholera.

Wala: A to ciekawe, czemu Krajaner się nazywa?

Pop: Bo pewnie kroi.

Mieciu: Jakie kroi? W Internecie było, że bilety już od złotówki so.

Młody: Ojcu, bedzie problem.

Mieciu: Co jest? Nie ma już biletów?

Młody: Bedzie problem $\mathrm{z}$ wylotem.

Mieciu: Bo co?

Młody: Bo za złotówkę wylot jest tylko z Wąchocka.

Mieciu: Ale to tam przecież chyba nie ma lotniska.

Młody: No to właśnie mówie, że bedzie problem z wylotem. 
[Śmiech popa.]

Młody: A z Krakowa wylot po 350.

Mieciu: Aj. Dobra, to trudno. 350 też tanio.

Młody: Tylko, że to bedzie podróż łączona.

Mieciu: No jaka?

Młody: Z Krakowa do Warszawy samolotem, a stamtąd na Sri Lankę samochodem.

Własnym.

[Śmiech.]

Mieciu: Mądry Ty jesteś, bedziesz samochodem na Sri Lankę jechał. Bezpośrednio znajdź.

Młody: Bezpośrednio 700 zł.

Wala: Oj.

Mieciu: Czekej, czekej. No dobra. Bierzemy. Starczy nam.

Młody: To super. Są pytania. Czy chcesz lecieć z walizką?

Wala: A ile to kosztuje?

Młody: Do 25 kilogramów 100 zł.

Pop: To już razem 800, masz tyle?

Mieciu: Sie cały rok oszczędzało, to sie ma.

Młody: Dobra, następne pytanie jest. Czy chcesz lecieć z walizką?

Mieciu: To już pytałeś.

Pop: No pytał.

Młody: To jest następne pytanie: Czy chcesz, aby twoja walizka leciała tym samym samolotem, co ty?

Pop: Ale pytanie!

Mieciu: No dajcie spokój. Humorystyczne te linie. Wala, zostajemy w domu.

Wala: Co?

Mieciu: Bedziemy sie opalać w zbożu.

Pop: A ja lece na basen.

Mieciu: A ja życze wszystkim słuchaczom RMF-u, żeby ich w wakacje nikt nie skrajanerowal.

Pop: Ja te $\dot{z}^{17}$.

Skecz, z uwagi na datę emisji, tuż przed rozpoczęciem wakacji, dotyczył perypetii bohaterów związanych ze zorganizowaniem zagranicznego wyjazdu. Niczym każdy przeciętny Polak, chcieli oni spędzić upragniony urlop w ciepłym kraju, oszczędzając jednocześnie na ten cel przez cały rok. Głównym jednak obiektem drwin stały się tanie linie lotnicze, które w audycji wystąpiły pod znaczącą nazwą Krajanair [w analogii do Ryanaira - popularnego taniego irlandzkiego przewoźnika, którego nazwa została skontaminowana z czasownikiem „kroić”

\footnotetext{
${ }^{17}$ Kabaret pod Wyrwigroszem, Stoneczne latanie, Radio RMF FM, 28.06.2012 r.
} 
w języku potocznym oznaczającym „okradać”]. Skecz w zabawny, hiperboliczny sposób obnażył chwyty stosowane przez linie lotnicze [efekt komiczny wzmocniło m.in. pojawienie się Wąchocka - znanego z licznych dowcipów o jego mieszkańcach], które w ostatecznym rozrachunku doprowadziły do zniszczenia marzeń bohaterów. W zamian zdecydowali się oni na wypoczynek na łonie natury. Całość została zaś zakończona - wspomnianym już - bezpośrednim zwrotem do słuchaczy.

Radio Zet z kolei od 11 kwietnia do 8 maja 2011 roku emitowało na swojej antenie krótką, kilkuminutową autorską audycję kabaretową pt. „Jak zostać królem dowcipu" prowadzoną przez aktora i satyryka Rafała Rutkowskiego. Autor pokazywał w niej, jak stać się zabawnym, a jednocześnie sam w takiej ludycznej roli występował. Jego poradnik, podobnie zresztą jak temat, któremu został poświęcony, miał bowiem charakter prześmiewczy, obfitował w żarty i zabawne opowieści.

Z kolei Radio Złote Przeboje od kilku już lat realizuje cykl pod nazwą „Kabaret Tygodnia", w którym wybrana grupa kabaretowa przez cały tydzień prezentuje słuchaczom swoją twórczość na antenie stacji. Do końca czerwca 2012 roku ukazywał się on w porannym programie „Złote Przeboje na Dzień Dobry”, w którym codziennie o godzinie 9.15 gwiazda danego tygodnia prezentowała dowcipne opowieści przygotowane specjalnie dla słuchaczy stacji. Pojawili się w nim m.in. Cezary Pazura, Kabaret Jurki, Tomasz Jachimek, Kabaret Made in China, Kabaret Młodych Panów, Kabaret Koń Polski czy Kabaret Smile [wcześniej autorski program w tej rozgłośni prowadził Kabaret Ani Mru Mru]. Cykl został następnie przesunięty na godzinę 9.20 i ukazuje się obecnie w audycji „Najśmieszniejsza godzina świata". Z kolei w latach 2011-2013 [począwszy od 1 kwietnia] na antenie Vox FM pojawiała się satyryczna audycja kabaretu OTTO pt. „I OTTO chodzi”, w sposób prześmiewczy komentująca aktualne wydarzenia.

Dość częstym obecnie zjawiskiem w rozgłośniach komercyjnych, zarówno w odniesieniu do audycji towarzyszących, jak i porannych, jest obsadzanie w roli prowadzących komików, artystów kabaretowych. Tak więc nie tylko goszczą oni w audycjach ze swoimi występami, ale stają się ich realnymi, regularnymi współtwórcami. I tak np. w Radiu RMF FM możemy usłyszeć Mariusza Kałamagę, byłego członka Kabaretu Łowcy.B [wym. Łowcy kropka be - przyp. P.Cz.W.] czy Roberta Korólczyka z Kabaretu Młodych Panów. Fakt ten zdaje się potwierdzać „urozrywkowienie" przekazu, nie tylko zresztą w omawianej w tym opracowaniu audycji towarzyszącej.

Podsumowując rozważania na temat kształtu muzycznej audycji towarzyszącej w rozgłośniach komercyjnych, uznałabym ją za formę mozaikową, polifoniczną, choć może nie tak dynamiczną i zróżnicowaną jak programy emitowane w paśmie porannym i popołudniowym. Czas nadawania audycji towarzyszących rządzi się bowiem nieco innymi prawami, co przekłada się na przebieg i atmosfe- 
rę programu. Można w nim jednak odnaleźć szereg form wskazujących, że i w tej części radiowej ramówki rozrywka jest chwytem pożądanym ze strony odbiorców i chętnie wykorzystywanym przez nadawców. Da się to zauważyć nie tylko wnikając w ich głąb, ale i przyglądając się im powierzchownie, choćby analizując nazwy bloków programowych Radia Zet, takich jak „Od ucha do ucha” [w domyśle „śmiać się”] czy „Muzyka, informacje, zabawa!”. Audycje towarzyszące z założenia zapewniają tło dla czynności wykonywanych codziennie w domu lub pracy, dostarczają również informacji i rozrywki, tym samym wpisują się w tendencję do zaspokajania wielu potrzeb w tym samym czasie.

\section{Bibliografia}

Krawczak E., Medialne formy spędzania czasu wolnego, [w:] ,Mate tęsknoty?” Style życia w czasie wolnym we wspótczesnym społeczeństwie, red. W. Muszyński, Wydawnictwo Adam Marszałek, Toruń 2009, s. 65-72.

Lisowska-Magdziarz M., Media powszednie. Środki komunikowania masowego i szerokie paradygmaty medialne w życiu codziennym Polaków u progu XXI wieku, Wydawnictwo Uniwersytetu Jagiellońskiego, Kraków 2008.

Łęcicki G., Integracyjna oraz dezintegrująca funkcja mediów w społeczeństwie informacyjnym, „Kultura - Media - Teologia” 2011, nr 4, s. 45-54.

Mroczkowska D., Szybkość i pośpiech jako źródła przyjemności, [w:] Kultura przyjemności. Rozważania kulturoznawcze, red. J. Grad, H. Mamzer, Wydawnictwo Naukowe Uniwersytetu im. Adama Mickiewicza, Poznań 2005, s. 113-129.

Muszyński W., Syndrom braku czasu we współczesnym społeczeństwie, [w:] „Nowy wspaniaty świat?" Moda, rozrywka i konsumpcja jako nowe style życia, red. W. Muszyński, Wydawnictwo Adam Marszałek, Toruń 2009, s. 7-19.

Piechota M., Strategie edutainment a sytuacja komunikacyjna, [w:] Nowe zjawiska w języku, tekście i komunikacji III. Kontekst a komunikacja, red. I. Matusiak-Kempa, S. Przybyszewski, Centrum Badań Europy Wschodniej UWM, Olsztyn 2011, s. 352-361.

Postman N., Zabawić się na śmierć. Dyskurs publiczny w epoce show-businessu, przekł. L. Niedzielski, Wydawnictwo Muza SA, Warszawa 2002.

Stachyra G., Gatunki audycji w radiu sformatowanym, Wydawnictwo Uniwersytetu Marii Curie-Skłodowskiej, Lublin 2008.

Szeja J.Z., Cywilizacja zabawy? Próba spojrzenia w przyszłość, „Homo communicativus” 2008, nr 3 (5), s. 147-154.

\section{Netografia}

Mleczko A., Widoki na weekend, [w:] Tydzień pod kreska, http://www.rmf.fm/ $\mathrm{au} / \mathrm{a}=\mathrm{bdp} \& \mathrm{p}=$ tydzien-pod-kreska\&pid=24 [dostęp: 13.07.2016] 
Paulina Czarnek-Wnuk

\section{Elements of entertainment in accompanying musical programming, for example, programmes from selected commercial broadcasters}

\section{(Summary)}

The article presents the form of accompanying musical programming in commercial radio broadcasters in Poland. It examines the questions of the place of entertainment in this kind of production, based on examples from a variety of stations, such as Radio Zet, RMF FM, Radio Eska, Radio Złote Przeboje or Vox FM. The text also refers to hybrid forms of media entertainment such as edutainment or democratainment. In the conclusion, this conglomerate radio genre is treated as a polyphonic, mosaic form, distinguished, though, by its dynamism and the nature of the programmes broadcast at the morning and afternoon peak hours of radio audiences.

Keywords: commercial radio, entertainment, music, accompanying programming. 